\title{
STIRLING-CYCLE THERMOMECHANICAL POWER SOURCES FOR REMOTE OR INACCESSIBLE COMMUNICATIONS SITES
}

E H Cooke-Yarborough

Instrumentation and Applied Physics Division, Atomic Energy Research Establishment, Harwell

ABSTRACT The paper deals with primary power sources for remote or inaccessible installations, requiring continuous power of tens or hundreds of watts electrical. It is shown that the relatively high conversion efficiency from heat to electricity which is provided by the stirling-cycle TMG can reduce the weight of fuel required at the site to about a quarter of the weight of equivalent primary batteries, with resultant operating economies. Two installations are in service in the field, and operating experience is being accumulated.

The TMG can also be used with radioi sotope heat sources, to provide power unattended for many years, as may, for example, be required by undersea repeaters. Again the relatively high efficiency of the TMG offers advantages of economy over the radioisotope thermoelectric generators used hitherto in undersea applications.

\section{INTRODUCTION}

As automatic weather stations, navigation aids and communication systems become deployed in the more remote and less technologically-advanced regions of the world, there is an increasing need for reliable, continuous sources of power for these installations. The power requirement is often in the region of tens to hundreds of watts, and it may not be possible to visit the site more frequently than once or twice a year. An installation may, therefore, consume something like 100 watt-years of energy between visits.

Where access to the site is difficult, requiring use of a helicopter, a small boat or even a packhorse, it is important to limit the weight of any fuel or batteries carried to the site. Similar considerations apply if the storage capacity on the site is limited, as may be the case, for example, in a weather buoy.

Solar cells or wind generators can, of course, generate electricity on site. However, these are not by themselves firm sources unless backed by secondary batteries of adequate capacity. The economic sizing of such systems depends upon good knowledge of the local weather, including likely year-to-year fluctuations. If this knowledge is not available substantial over-design may be necessary. It is beyond the scope of this paper to discuss in detail the pros and cons of such systems, except to note that a solarcell system at the higher latitudes may require backing by a secondary battery having a capacity of $10 \%$ of the annual energy demand, in order to average out the variations of sunlight between summer and winter. It will be seen from Table 1 that a nickel cadmium secondary battery of this capacity would weigh more than 4 tonnes per 100 watt-years of annual energy demand.

Table 1 also gives figures for the types of primary cell commonly used in remote installations. It is seen that it is necessary to carry 4 to 8 tonnes of battery to the site per 100 watt-years. The energy density of propane is about 100 times greater than that of these primary cells. The energy from burning this propane appears, however, as heat. Moreover, propane, being under pressure, has to be enclosed in a container which weighs almost as much as the propane itself. Thus we must divide the $50 \mathrm{MJ} / \mathrm{kg}$ of heat obtainable from propane by a factor of 2 to allow for the weight of the container, and by a further factor which takes into account the efficiency with which we can convert the heat into electricity.

Lines $3(b)$ and $3(c)$ of Table 1 give the electrical energy densities obtainable with conversion efficiencies of $2 \%$ and $10 \%$ respectively.

Thermoelectric materials are in principle capable of giving conversion efficiencies of $5 \%$ to $10 \%$, and even substantially higher with special materials under favourable circumstances, but the overall system efficiency is always lower, because of heat losses of various sorts. In a propane-heated system burner losses must also be taken into account. Because of 
heat losses in the flue, the efficiency of the burner may be no better than $60 \%$. The net effect is that a typical proprietary propane-heated thermoelectric power source may give an overall efficiency of about $2.4 \%$ if the $\mathrm{DC}$ voltage delivered by the thermocouples can be made equal to the desired load voltage. If, to obtain the right voltage, it is necessary to convert this DC voltage to $A C$ and then back to $D C$ at a different voltage, the efficiency may fall below $2 \%$. The figures given on line $3(\mathrm{~b})$ of Table 1 are, therefore, thought to be reasonably representative of what is obtainable with existing propane-heated thermoelectric systems. It will be seen that their energy density is comparable with that of primary cells, and that more than 6 tonnes of propane in containers would need to be carried to the site per 100 watt-years.

\section{PRINCIPLES OF THE TMG}

The Stirling-cycle thermomechanical generator (Refs 1,2) was developed at Harwell in order to improve on this low conversion efficiency by use of a dynamic system, without compromising the high reliability obtainable with static systems. In order to achieve this, all rotating members and sliding surfaces were eliminated, mechanical power output to drive a short-stroke linear alternator (Ref 3 ) being obtained from the deflections of a metal diaphragm (Refs 4,5 ). This and other flexing members are designed to be stressed to well below their fatigue limit (Ref 6 ).

The basic concept is shown in Fig 1 , which is reproduced from Ref 1 . A cylindrical displacer piston oscillates up and down on a spring suspension (not shown) inside a closed cylinder, the lower face of which is heated. This cylinder contains helium gas, and the displacer movement causes this helium to oscillate to and fro between the heated and cooled ends of the cylinder. The resultant oscillation in mean helium temperature results in an oscillating helium pressure. This pressure oscillation deflects the diaphragm and causes the permanent-magnet armature to oscillate between the fixed pole pieces, inducing oscillating voltages in the windings. The movement of diaphragm hub and armature induces a smaliamplitude reverse-phase oscillation of the spring-mounted machine body, and this serves to excite the springmounted displacer into oscillation at its natural frequency. Thus the feedback loop is completed and oscillation

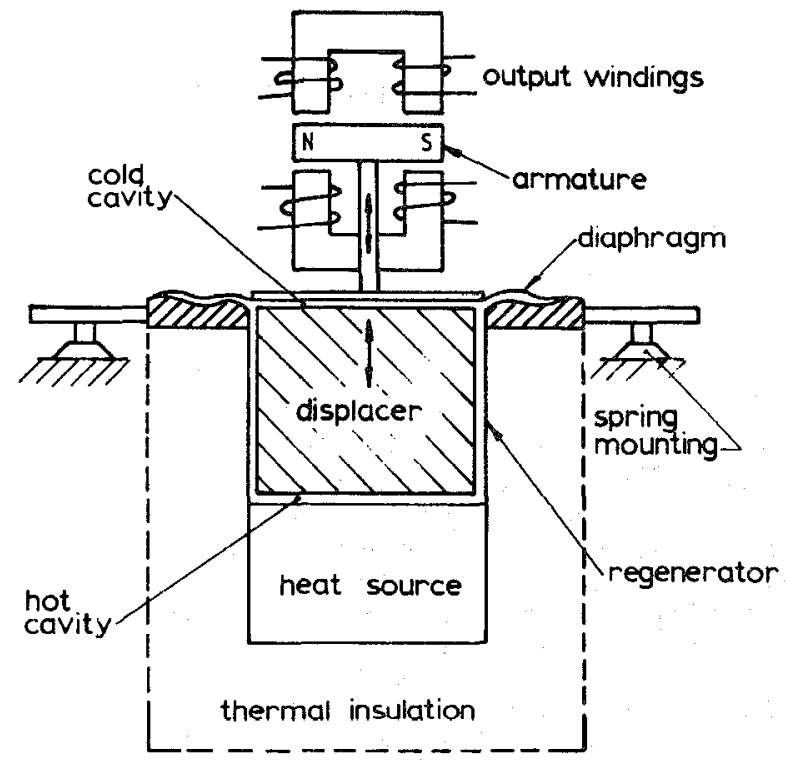

Fig 1 Basic configuration of the thermomechanical generator

sustained. Because of the absence of static friction, oscillation is selfstarting, as it would be in an electronic oscillator.

The reliability of properly-designed diaphragms was shown by a successful $2 \frac{1}{2}$ year continuous running test of an early experimental diaphragm (Ref 6 ), and the technical viability of the whole concept has been demonstrated by the successful continuous running of a radioisotopepowered thermomenchanical generator (Ref 7) since November 1974.

\section{FIELD EXPERIENCE}

The first field application of one of these generators began in 1975 in the UK National Data Buoy (Ref 8). This is a 25-watt generator with a fuel consumption of $200 \mathrm{~kg} /$ year, so half a tonne of propane (plus another half tonne for the containers) powers the Buoy for a 2-year mission without refuelling. Fig 2 shows the TMG being loaded into the Data Buoy in the summer of 1975 . It provided the major part of the Buoy's energy requirements during its first 18 months at sea. After a major refit in 1977 the Buoy is at sea again, with an improved TMG installation.

To meet the power requirements of a major lighthouse on the Irish Coast, the TMG was up-rated to $60 \mathrm{~W}$ by raising the pressure of the helium working gas and the operating temperature. Because neither burner nor TMG were optimized 


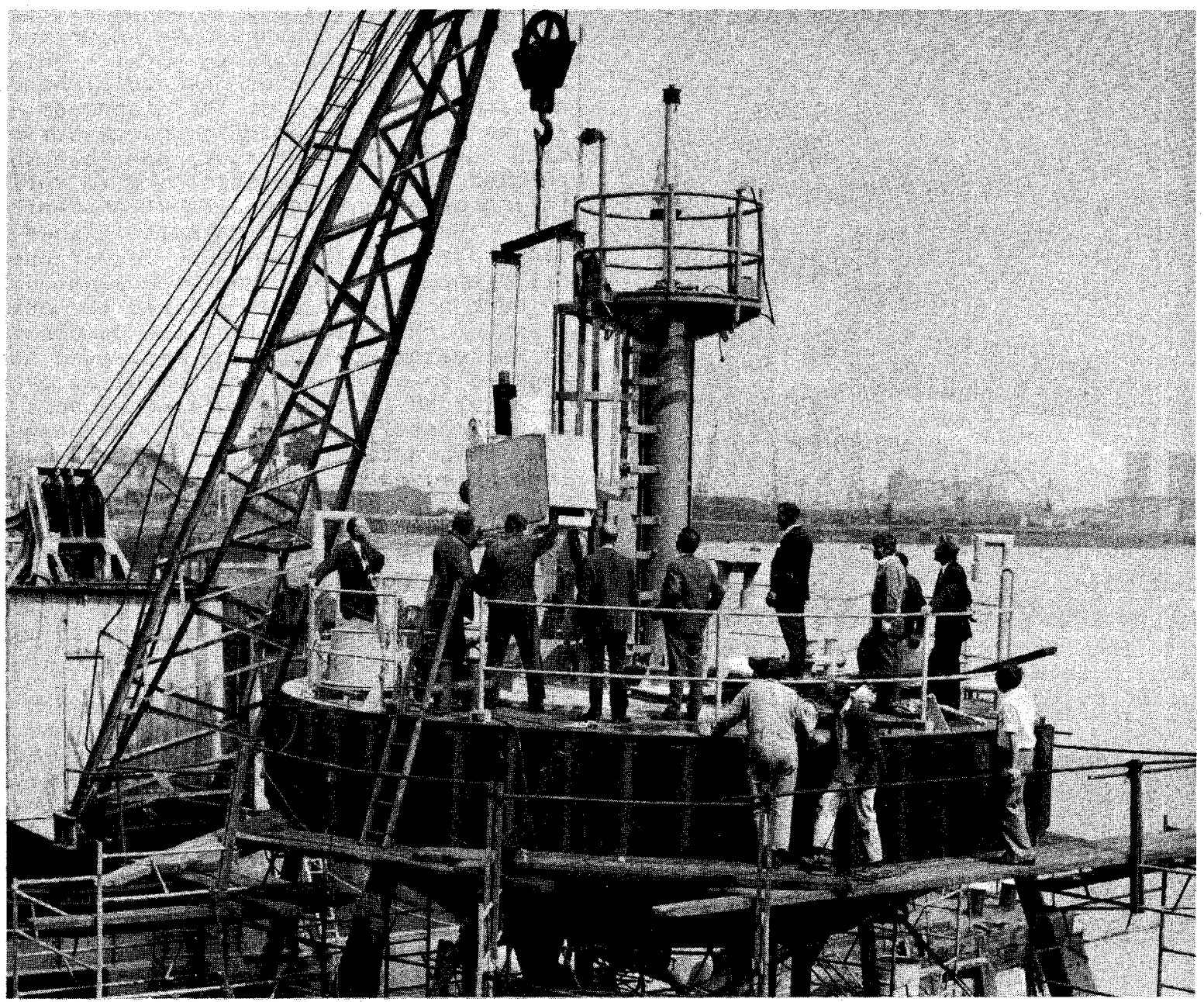

Fig 2 TMG being installed as the main power source in the UK National Data Buoy in 1975

for this operation the overall efficiency fell to about $9 \%$; nevertheless the system requires only about 0.9 tonnes of fuel annually (including containers), delivered by helicopter. Fig 3 shows the Iighthouse where this TMG is installed in the end of the long building nearest to the tower. Fig 4 shows the TMG installation in this building.

Table 2 summarizes the performance and operating record of the TMG's which have so far been built.

\section{INCREASED POWER}

It appears that the TMG has now reached the stage where it can be considered for communication purposes. However, most remote communications installations require rather more power than $60 \mathrm{w}$. Some consideration has been given to how the design could be up-rated to the region of $200 \mathrm{w}$ to $300 \mathrm{w}$. A crucial factor is the metal diaphragm which converts the cyclic helium pressure changes into the mechanical force and displacement which drives the linear alternator. At a given operating frequency the power delivered is proportional to the amount by which the diaphragm deflects and to the pressure difference appearing across the diaphragm. Both deflection and pressure stress the diaphragm, the maximum stress being radial bending stress round the rigid central hub. Since the resultant of these two stresses is already about $65 \%$ of the fatigue limit (Ref 6), it appears that we cannot abstract substantially more power from this type of diaphragm without either reducing the safety margin or increasing its already substantial diameter. Consequently, some attention has been given to an alternative design (Ref 9) in which the inner and outer edges of 


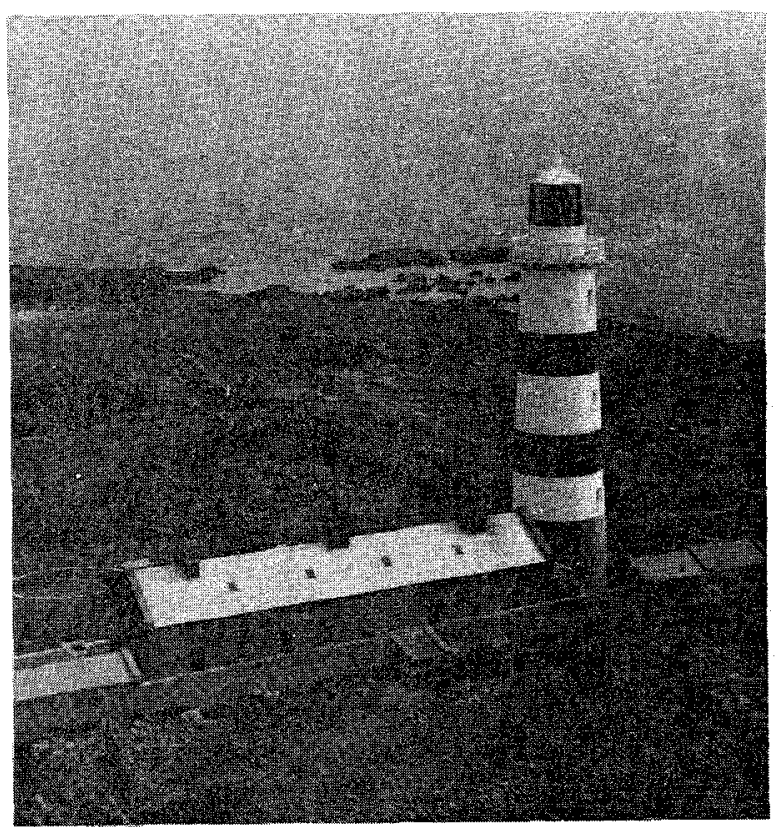

Fig 3 The lighthouse on the Island of Eeragh in Galway Bay, Eire. (Photo provided by Commissioners of Irish Lights.)

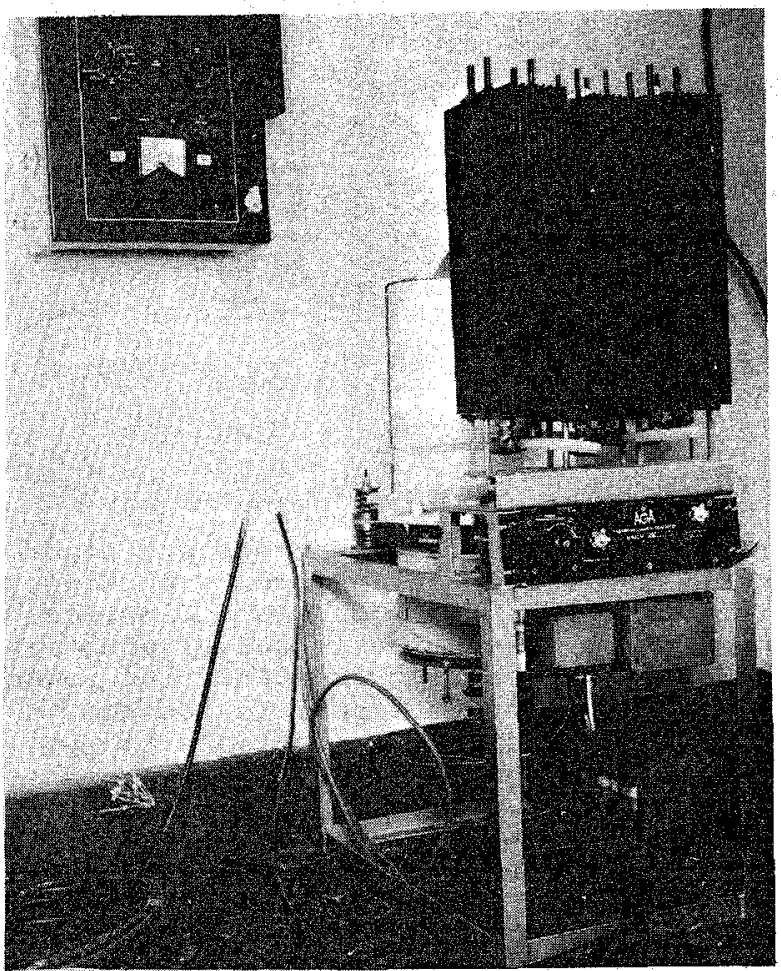

Fig 4 60-watt TMG installed at Eeragh lighthouse. Cooling radiator above: battery-charging control unit on wall behind. (Photo provided by AGA Navigation Aids Limited.) the diaphragm, instead of being rigidly attached to the hub and outer mounting, are connected flexibly to both. This immediately eliminates the radial bending stress at the edges of the diaphragm, and allows diaphragm design to be re-optimized, with the result that it is possible to use thicker diaphragm material and to deflect it a greater distance wi thout over-stressing. Use of thicker material allows the diaphragm to withstand much larger pressure differences without over-stressing. While we have not yet fully explored the optimization of this new design, the combination of increased pressure and increased stroke appears to offer an improvement by a factor of about 10 in power handling capacity. An incidental, but important advantage is that this articulated diaphragm is much less affected by radial temperature gradients, so the diaphragm material does not need to be corrugated to prevent variations in stiffness, and the stationary cavity plate does not, therefore, need to be shaped to fit these corrugations. This is an important practical advantage in machine manufacture.

It is, of course, important to ensure that reliability is not compromised by the flexible hinges at the inner and outer edges of the diaphragm. Preliminary calculations have been carried out on the basis that these hinges are of moderately hard rubber. These indicate that the strains in the rubber can, by choice of suitable dimensions, be limited to about one quarter of the fatigue limit (Ref 10). Moreover, the rubber will be in a helium atmosphere and not exposed to light, so surface degradation should not be a factor. To match the increased power resulting from increased swept volume and helium pressure, it will al so be necessary to increase the capacity of the burner and the cooling system. It appears, however, that the existing linear alternator is so conservatively designed that it could handle $250 \mathrm{~W}$ without significant modification.

Preliminary computations suggest that $200 \mathrm{~W}$ to $250 \mathrm{~W}$ should be obtainable from such a system with an overall efficiency (including burner) of at least 10\% (possibly approaching $20 \%$ with improved geometry). From line 3 (c) of Table 1 , it will be seen that just over $2 \frac{1}{2}$ tonnes of propane in containors taken to the site annualiy would meet the demands of a system with $10 \%$ efficiency. By comparison, between 7 and 18 tonnes of primary cells would be required to deliver $200 \mathrm{~W}$ for one year.

\section{UNDERSEA OPERATION}

Submerged cable repeaters pose a rather different problem, because no oxygen is avallable, and a 20-year life is required. These repeaters are normally powered from 
a direct current flowing along the cable from the $l$ and at one end to the $l$ and at the other end. The voltage difference appearing between the ends of the cable is the sum of the voltages required by all the repeaters. In the case of transoceanic cables, many thousands of volts are involved, and, in the interests of standardization, appropriate insulation has to be provided in each repeater. This considerably increases the cost and bulk of the repeaters. Future wide-band submarine cables may require repeaters to be more closely-spaced, perhaps raising the total voltage requirement at the 1 and ends of the cable to an impracticably high value. It may then be worth considering supplementing the power supplied at the cable ends by additional power generated autonomously on the sea-bed.

In this application air-depolarised batteries, and power sources involving combustion with air, are ruled out, and a radioisotope heat source appears to be the only energy source that could be seriously considered.

Strontium-90 is the cheapest radioisotope which has a sufficiently lorig half-life for this application. Despite the weight of the necessary shielding, a shielded $90_{\mathrm{Sr}}$ source has about ten times the energy density of propare. We carried out a design study in the early 1960's with Submarine Cables Limited to design a radioisotope-powered repeater, using thermoelectric energy conversion. It became clear that such a repeater would be too costly. More recently the successful operation of our experimental $90 \mathrm{Sr}$-powered TMG for more than $3 \frac{1}{2}$ years has led us to examine the possibility of a 500-watt (thermal) 90 Sr-heated power source, using a capsule of $90 \mathrm{Sr}$ derived from nuclear waste (Ref 11), for powering two TMG's, each delivering $26 \mathrm{~W}$ (Ref 7 ). The calculated overall efficiency was $12 \%$ at the beginning of the life of the radioisotope source.

Lines $4(\mathrm{a})$ and $4(\mathrm{~b})$ of Table 1 give the thermal and electrical power densities of such a system, allowing for the decay of the radioisotope source over 20 years. It will be seen that a 20-year radioisotope heat source weighs only a little more than a 1-year propane supply.

The recent up-rating of the TMG to $60 \mathrm{~W}$, and the availability of Waste-Management capsules delivering $1 \mathrm{~kW}$ of heat (Ref 11 ), lead us to believe that a $120 \mathrm{~W}$ submarine power source could be designed using minor advances on present technology.
Such sources would be too large and too costly for powering individual submarine repeaters. They could, however, each power several repeaters wi thout need of additional cabling, if they were inserted, as floating power sources, in series with the cable. In a system in which $6 \mathrm{kV}$ at $1 \mathrm{~A}$ is supplied at the cable land ends, each $120 \mathrm{~W}$ sea-bed power source would increase the possible cable length by $1 \%$. Using this arrangement, loss of power from one of the sources need not put the cable out of action, provided that the deficit in power could be made good by a corresponding increase in voltage at the land ends of the cable.

A programme of qualifying the $1 \mathrm{~kW}$ wasteManagement $90 \mathrm{Sr}$ heat sources for operation at the temperature required by an energy converter such as the TMG, is currently under way and may take several years to complete (Ref 11). Until this programme is completed, there appears to be no $90 \mathrm{Sr}$ available at economic prices. Nevertheless, if further investigation shows that a $90 \mathrm{Sr}$-powered submarine power source of the type described above to be economically attractive, then it would not be too early to start development in anticipation of the qualification of the Waste-Management sources.

\section{CONCLUSIONS}

To meet a continuous 100-watt electrical power demand at a remote or inaccessible site, the use of primary cells would involve carrying about 6 tonnes there annually. Secondary cells have an energy density about ten times worse, so even if they are used to back up solar cells, the initial installation may still require about 4 tonnes of secondary batteries.

The energy density of propare is about 50 times higher than that of primary cells, but the primary energy is in the form of heat, so an improvement over primary cells in electrical energy density is only obtained if the efficiency of conversion of heat to electricity exceeds about $2 \%$. The stirling-cycle thermomechanical generator can provide conversion efficiencies of $10 \%$ or greater, and evidence from 60,000 machine-hours operation is that reliability can be comparable with that of solid-state devices. It is, therefore, capable of reducing, by a factor of about 4, the weight of fuel which needs to be taken annualiy to the site. Substantial operating economies are therefore made possible. 
The thermal energy density of a shielded $90 \mathrm{Sr}$ radioisotope heat source can exceed that of propane by a further $f$ actor of at least ten, over a period of 20 years. The TMG allows electric power to be derived from this heat source with efficiency higher than that of the thermoelectric conversion used hitherto, so the amount of radioisotope and shielding required is substantially reduced. Such power sources may be important in undersea applications, such as submarine cable repeaters.

\section{ACKNOWLEDGMENTS}

The development of the 25-watt TMG from its laboratory stage to make it suitable for operation in the exacting environment of a buoy at sea was supported by the UK Department of Industry. The further development of the TMG to deliver $60 \mathrm{~W}$ AC was supported by $A G A$ Navigation Aids Limited of Brentford, England, to enable them to manufacture and install machines of this power.

\section{REFERENCES}

1 EH COOKE-YARBOROUGH, E FRANKLIN, $J$ GEISOW, R HOWLETT, CD WEST, "Thermomechanical Generator: an efficient means of converting heat to electricity at low power levels"; Proc IEE, Vol 121, No 7, July 1974 .

2 EH COOKE-YARBOROUGH, E FRANKLIN, $J$ GEISOW, R HOWLETT, CD WEST, "A new electrical power source for long-term unattended operation"; Record of the IEEE International Conference on Engineering in the Ocean Environment, August 1974 . (Also AERE Harwell report No R7753, May 1974.)

3. E FRANKLIN, "An assessment of the suitability of the inductor generator for use with the stirling-cycle thermomechanical generator"; AERE Harwell Memo No M2270, January 1970 .

4 EH COOKE-YARBOROUGH, "Diaphragm design for a thermomechanical generator"; AERE Harwell Memo No M2021, February 1968.

5 CD WEST, "Diaphragm calculations and design for the thermomechanical generator" AERE Harwell Memo No M2177, March 1969.

6 EH COOKE-YARBOROUGH, "Fatigue characteristics of the flexing members of the Harwell thermomechanical generator"; AERE Harwell report No R7693, March 1974.
7 EH COOKE-YARBOROUGH, FW YEATS, "Efficient thermomechanical generation of electricity from the heat of radioisotopes" Proc 10 th Intersociety Energy Conversion Engineering Conference, August 1975. (Also AERE Harwell report No R8036, May 1975.)

8 EH COOKE-YARBOROUGH, "A data buoy powered by a thermomechanical generator: results of a year's operation at sea"; Proc 12 th Intersociety Energy Conversion Engineering Conference, August/September 1977. (Al so AERE Harwell Memo No M2886, April 1977.)

9 EH COOKE-YARBOROUGH, "Articulated diaphragm"; Pat Appln No P 16178/75, Patents Ref $11433 \mathrm{AnH}$, Filed $18 \mathrm{Apl}, 1975$.

10 GJ LAKE, PB LINDLEY, "The mechanical fatigue limit for rubber"; J Applied Polymer Science, vol 9, pp 1233-1251.(1965)

11 HT FULLAM, "Strontium-90 fluoride data sheet"; Battelle Pacific Northwest Laboratory report No BNWL-2284, UC-4, -23 , October 1977.

12 "Industrial primary cells", data sheet issued by CIPEL (France).

13 "Nickel cadmium alkaline batteries", data sheet A150 issued by Chloride Alcad Limited (England). 
$1 \quad$ Primary cells (Ref 12)

(a) Ammonium chloride

$105 \quad 8 \cdot 8$

(b) Potash

150

$5 \cdot 8$

(c) Potash (requiring water to be added at

$240 \quad 3.6$

2 Secondary cells $(\operatorname{Ref} 13)$

$\mathrm{NiCd}$

$20 \cdot 3 \quad 43$

3 Propane (including containers)

(a) Thermal energy

7,000

(b) After converting heat to electricity at $2 \%$ efficiency

140

$6 \cdot 3$

(c) After converting heat to electricity at $10 \%$ efficiency

$700 \quad 1.26$

$4 \quad{ }^{90} \mathrm{Sr}$ radioisotope heat source (Ref 7)

(including nuclear radiation shield)

(a) Thermal energy over 20 years (allowing for radioisotope decay)

(b) After converting heat to electricity at $12 \%$ efficiency (Ref 7 ) 
PERFORMANCE OF THERMO-MECHANICAL GENERATORS

\begin{tabular}{|c|c|c|c|c|c|c|c|c|c|}
\hline \multirow{2}{*}{ Application } & \multirow{2}{*}{$\begin{array}{l}\text { Ser } \\
\text { No }\end{array}$} & \multicolumn{2}{|c|}{$\begin{array}{c}\text { Power output } \\
\text { watts }\end{array}$} & \multirow{2}{*}{$\begin{array}{l}\text { Propane } \\
\text { used } \\
\mathrm{kg} / \text { year }\end{array}$} & \multicolumn{2}{|c|}{ Efficlency } & \multirow{2}{*}{$\begin{array}{l}\text { Hot- } \\
\text { end } \\
\text { temp } \\
{ }^{\circ} \mathrm{C}\end{array}$} & \multirow{2}{*}{$\underset{\mathrm{H}_{\mathbf{Z}}}{\text { Freq }}$} & \multirow{2}{*}{$\begin{array}{c}\text { Running } \\
\text { hours } \\
\text { to July } \\
1978\end{array}$} \\
\hline & & AC & DC & & to $A C$ & to DC & & & \\
\hline Lab (propane) & $D_{1}$ & 31.75 & - & 196 & $10.2 \%$ & - & 480 & 110 & 9,000 \\
\hline Lab (1sotope) & $\mathbf{D}_{2}$ & 10.7 & - & $(138 w) *$ & $7.75 x$ & - & 280 & 83 & 30,000 \\
\hline Lab (electrical) & $D_{3}$ & 37.5 & 32.3 & $(222 W)^{+}$ & $16.9 \%$ & $14.5 \%$ & 594 & 100 & small \\
\hline Data Buoy (2) & $F_{1}$ & - & 27.0 & 166 & - & $10.7 \%$ & 493 & 108.8 & 8,000 \\
\hline Data Buoy $(1)$ & $\boldsymbol{F}_{2}$ & 24.5 & 18.9 & 190 & $8.1 \%$ & $6.25 \%$ & 445 & $115^{x}$ & 10,000 \\
\hline AGA (original) ) & & - & 18.46 & $\leftarrow$ not & measure & - & 451 & $112^{x}$ & small \\
\hline AGA (uprated) & & 65.0 & - & 450 & $9.1 \%$ & - & 603 & 105 & 2,000 \\
\hline $\begin{array}{l}\text { AGA for } \\
\text { Trinity House }\end{array}$ & $F_{5}$ & 31.2 & 24.66 & 164 & $12 \%$ & $9.5 \%$ & 482 & 107 & small \\
\hline
\end{tabular}

- Radloisotope $90_{S r}$ (power as in Nov 1974)

4. Electrically heated

$x$ Displacer without baffles 